\title{
К ВОПРОСУ ОБ АРХЭ АНАКСИМАНДРА: АРИСТОТЕЛЬ КАК ИСТОЧНИК СВЕДЕНИЙ ОБ АНАКСИМАНДРЕ
}

\section{K.В. Райхерт}

В среде философов, антиковедов и классических филологов традиционно / общепринято / привычно мнение, будто Анаксимандр Милет-

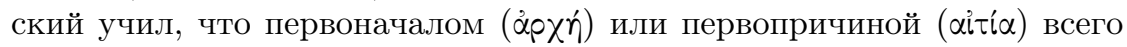

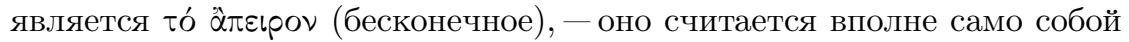
разумеющимся.

Однако есть четыре мнения, которые идут против сложившейся

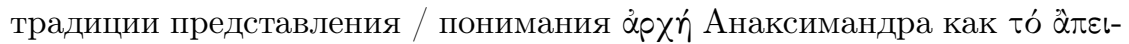
роv. Эти четыре мнения можно назвать прецедентами в истории изучения досократической философской мысли. Вот они:

(1) Валентин Розе утверждал, что тó а̀лєıро есть не что иное, как термин Аристотеля. Действительно, если верить свидетельству псевдо-Аристотеля (DK12A 13), Анаксимандр, как и его «учи-

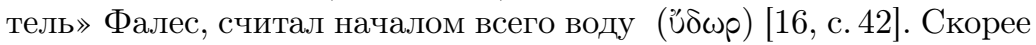
всего, такое представление В. Розе об а́рхи́ Анаксимандра было связано с эйфорией от открытия данного свидетельства псевдоАристотеля [DK12A 13].

(2) Роберт Айзлер, отправляясь от «Метеорологии» Аристотеля

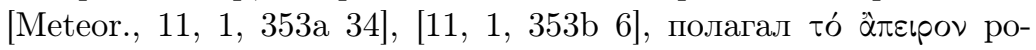
довым понятием а̇рхи́ в семантике Стагирита. По его мнению, Анаксимандр началом считал Хро́vos (время) [11, с. 506].

(3) А.В. Лебедев думал, что «тó àтєıро (субстантивированное через артикль прилагательное среднего рода единственного числа) - 
этот стабильный термин Аристотеля, - ни разу не встречается в аутентичных фрагментах (цитатах verbatim из) досократиков» [6, с. 43]. В статье, посвященной реконструкции космогонического учения Анаксимандра, - «TO APEIRON: Не Анаксимандр, а Платон и Аристотель», А.В. Лебедев ставит вопрос об аутентичности термина тó àлєıроv, то есть о принадлежности данного термина лексикону милетского философа. Лебедев утвержда-

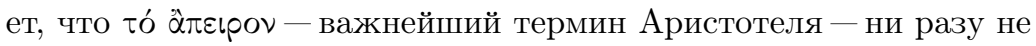
встречается во фрагментах ранних греческих философов. И это не случайно: для досократиков, включая Анаксимандра, слово

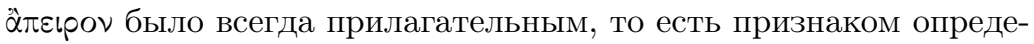
ленного существительного. Субстантивация этого прилагательного произошла в эпоху Платона. Значит, ӓлєьро ни в коем разе не может быть по Анаксимандру обозначением начала а’рхи́, источником возникновения мира, универсума; скорее, а̀лєьро является термином собственно категориально-понятийного аппарата Аристотеля. Сам же А.В. Лебедев считал «началом» Анаксимандра Хро́vos. Любопытно, что единственно сохранивший фрагмент анаксимандрова текста (DK12B 1) дает повод для такого рода предположений:

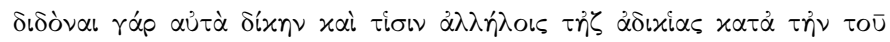

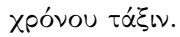

Изречение Анаксимандра можно перевести / истолковать следующим образом:

они [вещи?] устанавливают бín (указание посредством непререкаемого слова на то, что должно иметь место, приговор) и тібьљ

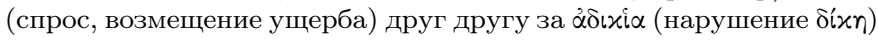

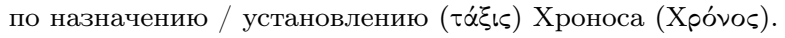

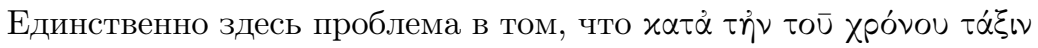
(в порядке времени) является стереотипной фразой Аристотеля и перипатетиков, как в принципе и первая часть изречения Анаксимандра

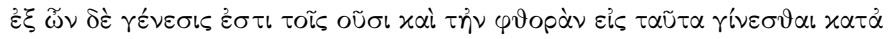

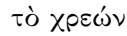

может быть переведена как

из чего вещам рождение, в то и гибель им по необходимости. 
Оба текста насыщены характерными для понятийно-категориального аппарата Аристотеля и перипатетиков понятиями оن่бı̀

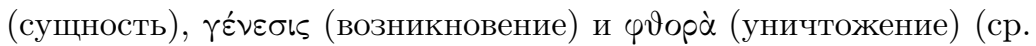
с пассажем в «Метафизике»:

Из чего все сущие [= вещи] состоят, из чего, как из первого, они возникают и во что, как в последнее, они уничтожаются [Metaph., I, 3, 983b 6]).

(4) Т.Г. Синниг также высказывает сомнение по поводу аутентичности Анаксимандрова термина ӓлєьроv, но, в отличие от А.В.Лебедева, он не приводит детального историко-филологического анализа данного термина [18, с. 1-14].

Как можно видеть, в этих четырех случаях исследователи склонны

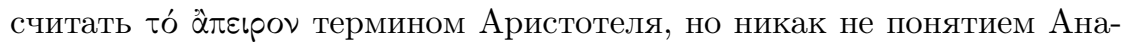
ксимандра. Если это так, то я имею полное право поставить вопрос, ответ на который и составляет цель данного исследования: «Что в действительности Аристотель полагал как а’рхй Анаксимандра?» Другими словами, проблема в самом общем виде может быть сформулирована как поиск того архэ, которое именно Аристотель приписывает Анаксимандру. В данном случае я не ставлю себе цель выявить аутентичное «начало» Анаксимандра, но показать то, что, по мнению Аристотеля, могло быть этим «началом».

Если просмотреть все сохранившиеся тексты Аристотеля, то можно увидеть, что во всех них Стагирита интересуют только первые и истинные положения, точнее возможность их выявления, построения и адекватной оценки. Следует говорить не просто о первых и истинных положениях, но о положениях наук, таких как «физика» и логика (аподиктика, диалектика). В определенном смысле здесь Аристотель идет вслед за своим учителем Платоном, применяя метод диалектики: по Платону, «диалектика» состоит в рассмотрении самого принципа

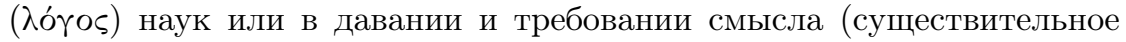
خóүos) для чувственных вещей [Pl., Res., VII, 531d-537c; Pl. Lac., 187 d-e; Pl. Taeat., 169 a, 177b; Pl., Phaed., 76 b, 101 c-d; Pl., Phil., 26b] — такого рода метод предусматривает рассмотрение различных мнений по спорному вопросу и получение в качестве результата либо правдоподобного как чего-то среднего, либо вообще ничего [3, с. 24-37; 7, с. 274-286, 740-752], [12, с. 29-348], [13], [14], [15], [17]. Тем же, по сути, занимается и Аристотель: он разбирает мнения по спорным, неразрешенным и, возможно даже, неразрешимым вопросам [Arist., De soph., 176b 15-17], 
к которым относятся апории первой философии и начала доказывающих (дедуктивных) наук. О них, как правило, имеются противоположные и вместе с тем одинаково правдоподобные мнения. Какому из них отдавать предпочтение? Какое из них выбрать в качестве начала данной науки? По Аристотелю, на эти вопросы нельзя ответить, апеллируя к опыту или доказательству (силлогизму). Единственный способ, с помощью которого можно приблизиться к решению таких задач - это диалектическое (диалогическое) обсуждение каждого из мнений упомянутого характера, оценивающее данное мнение по следствиям, вытекающим из него, и принимающее или отвергающее его. Однако диалектическое (диалогическое) обсуждение нередко оканчивается безрезультатно, и только благодаря этому удается нам иногда возвыситься до того рода познания, перед которым (и только перед которым) открыты высшие истины. Этот род познания есть ум (умозрение (voūs) [Arist., Anal. Post., 100b 5-7]).

Не отступает от применения диалектики Аристотель и при рассмотрении мнений своих предшественников-условно их обозначим как «доаристотелики». Основными текстами Аристотеля, в которых представлены философские учения доаристотеликов, можно считать «Физику» и «Метафизику»: «Физика» посвящена рассмотрению пер-

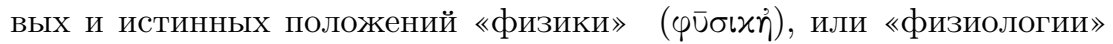

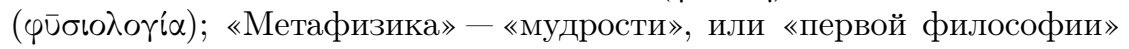

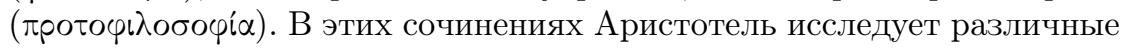
мнения своих предшественников на предмет выявления первых и истинных положений вышеназванных наук. По этому поводу интересно одно замечание А.В. Лебедева в его статье, посвященной Фалесу Милетскому:

Разбор «мнений предшественников» в Metaph. A 3-9 как и любой ана-

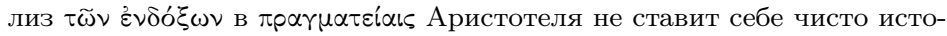
рических целей и должен служить диалектическим аргументом о четырех $\alpha i \tau i \alpha l$ или $\alpha$ рх $\alpha i$ бытия: никто из предшественников не вышел за рамки «четырех причин» или «начал», каждый предвосхитил только одно из них [5, с. 167].

Так или иначе, в результате Аристотель приходит к отказу от использования этих «неправдоподобных» философских учений и построению собственного.

По мнению Аристотеля,

большинство первых философов считало началом всего одни лишь материальные начала, а именно то, из чего состоят все вещи, из чего как 
первого они возникают и во что как в последнее они, погибая, превращаются, причем сущность хотя и остается, но изменяется в своих проявлениях, - это они считают элементом и началом вещей. И потому они полагают, что ничто не возникает и не исчезает, ибо такое

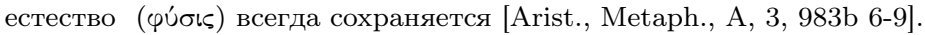

Другими словами, Стагирит полагал, что доаристотелики исследовали только материю («то, из чего» (ì $\lambda)$ ), в то время когда остальные виды первоначал (сущ. ед. ч. $\alpha$ рхй) или первопричин (сущ. ед. ч. aiтi $\alpha$ ) - а именно: форма, цель и действие (движущее), оставались за рамками их рассмотрения. В принципе это легко объяснимо: учение о 4-х первоначалах было создано Аристотелем; его предшественники просто не знали такого учения. Мнение Аристотеля, что его предшественники занимались исследованиями материальных первопричин, можно объяснить: те архэ, которые предлагают доаристотелевцывода (Фалес), воздух (Анаксимен), огонь (Гераклит), все четыре элемента (Эмпедокл), числа (пифагорейцы), атомы (Левкипп, Демокрит), гомеомерии (Анаксагор), - не что иное, как тела (сущ. ед. ч. бテّ $\mu \alpha)$,

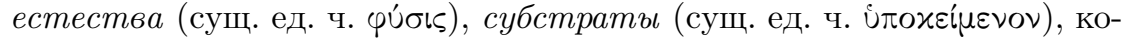
торые, по мысли Аристотеля, являются характеристиками материи (ن̀خ), или материальных первопричин.

Необходимо отметить, что архэ, о которых учат доаристотелевские философы, могут иметь форму, но эта форма является результатом выделения из них множества единичных вещей. Здесь я имею в виду, что то или иное архэ приобретает форму только тогда, когда возникают единичные вещи. Однако в контексте аристотелевской филосо-

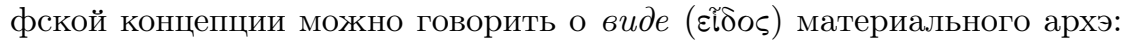
גрхй Фалеса имеет вид воды, Анаксимена - воздуха, Гераклита - огня, пифагорейцев - числа [Arist., Metaph., I, 3, 983b]. Единственно здесь возникает проблема с видом «начала» по Анаксимандру: из текстов Аристотеля не ясно, какой из элементов (вода, воздух, огонь, земля) Анаксимандр принимает в качестве $\alpha$ рхй. Кстати, это вызывало немало затруднений у доксографов (историков философии), которые в той или иной степени опирались на труды Аристотеля: одни (такие, как Симпликий) считали, что Аристотель оставил «начало» Анаксимандра без определений [10, с. 121]; другие же (такие как Александр Афродизийский), ссылаясь на тексты самого Аристотеля [Metaph., A, 7, 988a 29; Phys., A, 4, 187a 12], принимали в качестве начала «природу среднего между воздухом и огнем или между воздухом и водой (о ней говорится и так, и так)» [10, с. 120]. Были и такие, как Ипполит, которые считали, что тó àлєıро и есть архэ Анаксимандра [10, с. 120]. 
Собственно мнение по этому вопросу последних и возобладало в истории философии.

Любопытно, что в сохранившихся текстах Аристотеля можно условно выделить ряд критериев для классификации доаристотелевских философских учений. Здесь я не буду рассматривать их все; меня интересует всего один из таких критериев.

В главах 4-8 III книги (Г) «Физики» Аристотель анализирует поня-

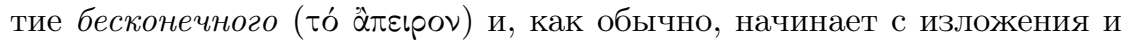
критики взглядов предшественников, которые должны служить диалектическим аргументом в пользу его собственного понимания тó äлєıро . Здесь необходимо вернуться к фрагменту из «Метафизики» Аристотеля [A, 3, 983b 6], в котором сказано: «то, из чего состоят все вещи, из чего как первого они возникают и во что как в последнее они, погибая, превращаются, причем сущность хотя и остается, но изменяется в своих проявлениях». Из этого пассажа следует, что если а́рхи́

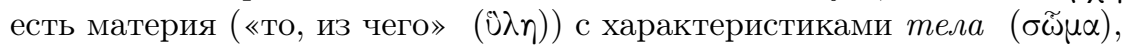

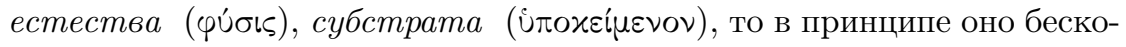
нечно, то есть выступает как бесконечное тело, бесконечное естество, бесконечный субстрат.

Именно бесконечное оказывается критерием для одной из аристотелевских классификаций предшествующих учений. Так, Аристотель считает:

Все, кто только заслуживающим внимания образом занимался натуральной философией («физикой»), толковали о бесконечном и все полагают его неким ঝ̊рхй, но только одни, как, например, пифагорейцы и Платон,-о бесконечном в себе, [то есть] не как об акциденции чего-то другого, но как о самосущей субстанции [Arist., Phys., Г, 4, 202b 37-39].

Из данного пассажа следует, что Аристотель разделял доаристотеликов на тех, кто принимал в качестве аррхи́ бесконечное как самостоятельную сущность, и тех, кто полагал бесконечное как акциденцию какой-то сущности. K первым Стагирит относил пифагорейцев и Платона, ко вторым - всех остальных (Фалеса, Анаксимена, Гераклита, Ксенофана, элейцев, Эмпедокла, атомистов, Анаксагора). Ко вторым Аристотель относил и Анаксимандра. Таким образом, получается, что,

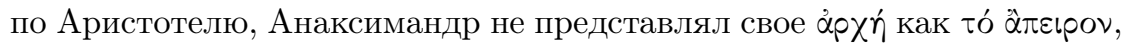

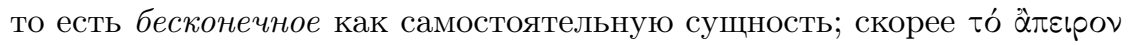
выступало как акциденция. Любопытно, что в главах 4-8 III книги (Г)

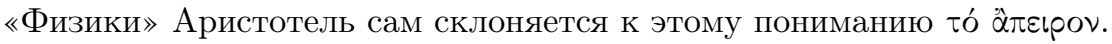


Известно, что «акциденция»- это русская калька латинского слова accidens. Само слово accidens является буквальным переводом на

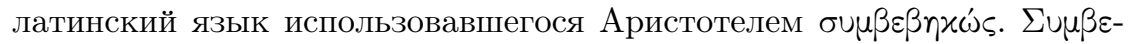
$\beta \eta x \omega ́ s$, древнегреческое слово, на русском языке имеет ряд переводных значений: акциденция, сходство, случай, случайность, привходящий признак, даже прилагательное.

Исходя из вышесказанного, можно подумать, что, по Аристотелю,

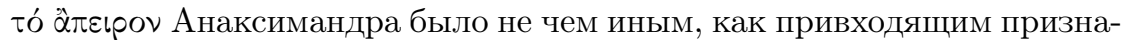
ком или просто свойством какой-то сущности (oひ่ఠı̀). В таком случае и возникает правомерный вопрос: «Что Аристотель считал а́рхи́ Анаксимандра?».

Существует два фрагмента, в которых Аристотель показывает, что в отношении архэ Анаксимандра он однозначен:

А другие утверждают, что противоположности наличествуют в Одном и выделяются из Него, как говорит Анаксимандр, равно как и все, кто принимает Одно и многое, как, например, Эмпедокл и Анаксагор: ведь и по их мнению, так же (как и по мнению Анаксимандра), остальные [тела] выделяются из смеси [Arist., Phys., A, 4, 187a 20].

Все возникает из сущего, но только сущего в возможности, а в действительности - не сущего. Именно это означает Одно Анаксагора (так лучше, чем «все вперемешку»), и «смесь» Эмпедокла и Анаксимандра [...] Так что они, пожалуй, толковали о материи [Arist., Metaph., $\Lambda, 2,1069 \mathrm{~b}$ 19].

Из этих двух фрагментов становится ясно, что Аристотель под

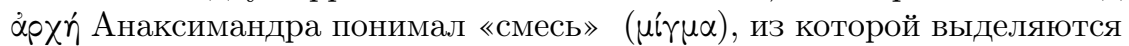
противоположности. Эти-то противоположности и составляют основы всех вещей, субстанций.

Интересно, что нигде в известных текстах Аристотель не сообщает, какие именно противоположности выделяются из «смеси» Анаксимандра, и это в то время, когда Стагирит показывает, что по Эмпедоклу из «смеси» выделяются четыре «корня» (элемента): вода, воздух, огонь, земля. Этот момент можно объяснять по-разному. Например, можно объяснить это тем, что Аристотель смутно представлял себе, каково же в действительности архэ Анаксимандра. Это может быть связано с тем, что уже Аристотелю не были доступны сочинения самого Анаксимандра, если, конечно, эти сочинения в действительности существовали. Может быть такое, что Аристотель всю свою информацию о философии Анаксимандра получил из какого-то неизвестного нам устного источника. Странным является и тот факт, что сочинения 
Аристотеля - это самый ранний из доступных нам источников сведений об Анаксимандре.

Другое объяснение может быть таким: учение Анаксимандра было сходно с учениями некоторых орфиков, таких как Лин (VII-VI вв. до н. э.), у которого можно прочитать следующее: «Было некогда время, когда все вещи были вместе» (DL, I, 4). Именно это «все вещи были вместе» Аристотель мог счесть в качестве «смеси».

Итак, согласно Аристотелю, Анаксимандр учил, что в начале всего была «смесь» $(\mu i \gamma \mu \alpha)$ и что именно из нее выделились все вещи.

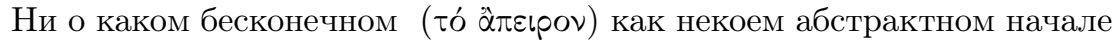
$\left(\dot{\alpha} \rho \chi \eta^{\prime}\right)$ в сохранившихся текстах Аристотеля не говорится. Кроме того,

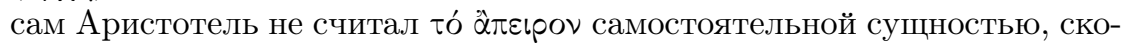

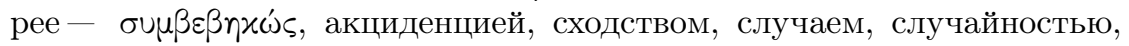
привходящим признаком. Учитывая, что из всех известных антиковедению текстов, в которых сообщается об Анаксимандре и его философском учении, по времени сочинения Аристотеля являются наиболее ранними, можно допустить, что они оказались источниками не только сведений о философии Анаксимандра, но и некоторых заблуждений

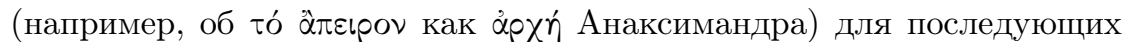
исследователей ранней философской мысли; причем эти заблуждения были не намеренным искажением предлагаемых сведений самим Аристотелем, но порождениями самих читателей и интерпретаторов, возможно - следствием их невнимательности или недостаточно развитой методологии работы с текстами. Однако это допущение требует более тщательного исследования.

\section{Принятые сокращения:}

Arist. - Aristoteles, Аристотель (сочинения: Anal. Post. = Analytica posteriora, Вторая аналитика; De soph. = De sophisticis elenchis, O софистических опровержениях; Metaph. = Metaphysica, Метафизика; Phys. = Physica, Физика).

$D K$ - Diels-Kranz, Дильс-Кранц «Die Fragmente der Vorsokratiker», русск. изд. «Фрагменты ранних греческих философов».

$D L$ - Diogenes Laërtius, Диоген Лаэртский «О жизни, учениях и изречениях знаменитых философов».

Pl. - Plato, Платон (диалоги: Lac. = Laches, Лахет; Phaed. = Phaedo, Федон; Phil. = Philebus, Филеб; Res. = Republica, Государство; Theaet. = Theaetetus, Teэтет).

\section{Литература}

[1] Аристотель. Сочинения: в 4-х тт. - М. : Мысль, 1976-1983. 
[2] Ахманов А.С. Логическое учение Аристотеля.-М.: Изд. соцэкон. литературы, 1960.

[3] Диллон Д. Наследники Платона: исследование истории Древней Академии (347-274 ВС). - СПб. : Изд. СПБГУ, 2005.

[4] Диоген Лаэртский. О жизни, учениях и изречениях знаменитых философов. - М. : Мысль, 1989.

[5] Лебедев А.В. Об изначальной формулировке традиционного тезиса Фалеса THN APXHN ГАОП EINAT // Balcanica. Лингвистические исследования. - М. : Наука, 1979. - С. 167-176.

[6] Лебедев A.B. TO AПEIPON: не Анаксимандр, а Платон и Аристотель // Вестник древней истории. - 1978. - № 1. - С. 39-53.

[7] Лосев А.Ф. История античной эстетики. Софисты. Сократ. Платон. - М. : АСТ; Харьков: Фолио, 2000.

[8] Мигунов А.И. Аналитика и диалектика: два аспекта логики Я.А. Слинин и МЫ: к 70-летию профессора Ярослава Анатольевича Слинина. - СПб. : Санкт-Петербургское философское общество, 2002. - С. 326-340.

[9] Платон. Сочинения: в 4-х тт. - М. : Мысль, 1990-1994.

[10] Фрагменты ранних греческих философов. Ч.1. От эпических теокосмогоний до возникновения атомистики / сост. пер. с др.-гр. и лат. А.В. Лебедев. - М. : Наука, 1989.

[11] Eisler R. Weltenmantel und Himmels Zeit. Religionschchtliche unter suchuhgen zur Urgeschichte des antiken Weltbildes. - Bd. 2. Munchen, 1910.

[12] Findlay J.N. Plato. The Written and Unwritten Doctrines. - London : Routledge \& Keagan Paul; New York: Humanities Press, 1974.

[13] Gerhard W. A. Plato's Theory of Dialectic // New Scholasticism. 1947. — № 21. - C. 192-211.

[14] Lutoslawski W. The Origin and Growth of Plato's Logic, with Account of Plato's Style and of Chronology of His Writings. - London: Longman's, 1905. 
[15] Mueller G.E. Plato's Dialectical Idealism // Monist. - 1935. № 45. - C. 199-219.

[16] Rose V. De Aristotle librorum ordine et auctoritate commentatio. Berolini: Reimer, 1854.

[17] Shorey P. The Origin of Syllogism // Classical Philology. - 1924. № 19. - C. 1-9.

[18] Sinnige T.G. Matter and Infinity in the Presocratic Schools and Plato. - Assen : H.J. Prakke and H.M.G. Prakke, 1968.

Надійшла до редакціӥ 11 березня 2014 р. 